\title{
Short-term daily steps increment enhances submaximal exercise tolerance in healthy insuficiently active men
}

\section{Incremento em curto prazo no número de passos diários melhora a tolerância ao exercício submáximo em homens saudáveis insuficientemente ativos}

Luiz Guilherme G. Porto'

Keila E. Fontana²

Guilherme E. Molina ${ }^{3}$

Guilherme Rocco 4

Luiz Fernando Junqueira J. ${ }^{5}$

\section{ABSTRACT}

The 10000 steps/day message has been proposed as a minimum steps/day target for healthy adults. Nevertheless, this target does not seem feasible as an initial goal for inactive adults. New strategies to progressively increase daily steps should be evaluated. The study evaluated the effectiveness of increase a pedometer-measured 3500 steps/day on physical performance at anaerobic threshold (AT). Nineteen healthy insufficiently active men, 19-46 yrs, wore a pedometer for 2 weeks to quantify their habitual daily steps at baseline. Afterwards, subjects were instructed to increase 3500 steps/day above baseline during 3 weeks (intervention). Cardiopulmonary exercise stress tests (CPX) were performed before and after the intervention. Submaximal exercise tolerance was analyzed by the heart rate at AT (HR-AT), the oxygen uptake at AT (VO2-AT), the time spent on CPX until AT onset and the reached distance. Nonparametric statistics were applied, expressing the results as median and minimum and maximum values. The variables were pair-wised compared by the Wilcoxon test. The differences were considered statistically significant when a two-tailed $P$-value was less than $5 \%$. At baseline, median (min-max) of daily steps was 7295 (4700-14752 steps), whereas it was 11772 (8998-18620 steps) after the intervention ( $\mathrm{p}=0.0001)$. On CPX, time until AT onset was higher after (359s; 179-521s) than before daily steps improvement (340s; 208-436s) ( $\mathrm{p}=0.027)$. Similarly, the distance attained at AT was higher after $(398.6 \mathrm{~m} ; 165.6-637.5 \mathrm{~m})$ than before the intervention $(372.2 \mathrm{~m} ; 197.8-528.8 \mathrm{~m})(\mathrm{p}=0.014)$. The increment of 3500 steps/day above baseline, during three weeks, was effective for improving exercise tolerance at AT.

\section{KEYWORDS}

Walking; Pedometer; Physical activity; Inactivity; Health promotion.

\begin{abstract}
RESUMO
A mensagem dos 10000 passos diários tem sido proposta como meta mínima de passos para adultos saudáveis. Entretanto, esta meta parece não ser factível como objetivo inicial para homens inativos. Novas estratégias de aumento progressivo nos passos diários devem ser avaliadas. Este estudo avaliou a eficácia do incremento de 3500 passos por dia, medidos por pedômetro, no desempenho físico no limiar anaeróbico (LA). Dezenove homens saudáveis insuficientemente ativos, 19-46 anos, usaram um pedômetro por 2 semanas para quantificar o padrão habitual de passos diários. Em seguida, foram orientados a aumentarem 3500 passos/dia acima do padrão usual, durante 3 semanas (intervenção). O teste de esforço cardiopulmonar (TE) foi realizado antes e após a intervenção. A tolerância ao esforço submáximo foi avaliada pela frequência cardíaca no $L A(F C-L A)$, o consumo de oxigênio no $L A(V O-L A)$, o tempo e a distância percorrida até o LA. Estatística não-paramétrica foi usada, expressando-se os resultados como mediana e valores mínimo-máximo. As variáveis foram comparadas de forma pareada pelo teste de Wilcoxon. As diferenças foram significativas quando o valor bi-caudal de $P$ foi menor que $5 \%$. A mediana (min-max) antes da intervenção foi de 7295 (4700-14752 passos), enquanto após a intervenção foi de 11772 (8998-18620 passos) ( $p=0.0001)$. No TE, o tempo até o LA foi maior (359s; $179-521 s)$ depois que antes do aumento de passos (340s; 208-436s) (p=0.027). Da mesma forma, a distância percorrida até o LA foi maior após $(398.6 \mathrm{~m} ; 165.6-637.5 \mathrm{~m})$, comparativamente a antes da intervenção $(372.2 \mathrm{~m} ; 197.8-528.8 \mathrm{~m})(p=0.014)$. O incremento de 3500 passos por dia acima do padrão habitual, durante três semanas, foi eficaz para aumentar a tolerância ao exercício no LA.
\end{abstract}

Rev Bras Ativ Fis Saúde p. 98-108 DOI:

http://dx.doi.org/10.12820/rbafs.v.19n1p98

1 Faculty of Physical Education, Cardiovascular Laboratory - Faculty of Medicine and Postgraduate Course of Medical Sciences, University of Brasilia, Brasilia, DF, Brazil

2 University of Brasilia Faculty of Physical Education and Postgraduate Course of Physical Education, Brasilia, DF, Brazil

3 Faculty of Physical Education, Cardiovascular Laboratory - Faculty of Medicine - University of Brasilia, Brasilia, DF, Brazil

4 University of Brasilia Faculty of Physical Education and Postgraduate Course of Physical Education, Brasilia, DF, Brazil

5 Cardiovascular Laboratory, Cardiology Division, Clinical Medicine Area and Postgraduate Course of Medical Sciences, University of Brasilia Faculty of Medicine, Brasilia, DF, Brazil 


\section{INTRODUCTION}

The association between regular physical activity practice and health has been well established since the early 50's, particularly with regard to the prevention of cardiovascular diseases ${ }^{(1,2)}$. The known benefits of an active life style have supported several health intervention programs with the main purpose of reducing physical inactivity, which is one of the major public health problems and modifiable health risk factors worldwide ${ }^{(3)}$. Despite several initiatives to promote physical activity (PA) and to evaluate adherence and dose-response issues ${ }^{(4)}$, changing physical activity behavior is still a great challenge ${ }^{(5)}$. In the challenging scenario, walking appears as a simple, practical and safe PA modality that could be stimulated in public health programs ${ }^{(6,7)}$ and as an effective form of preventive medicine ${ }^{(8)}$. Apart from that, walking programs that use pedometers as an intervention tool seem to be effective in increasing walking patterns at the community level ${ }^{(9)}$

The shift from the continuous exercise paradigm to the new concept of accumulated $\mathrm{PA}^{(1)}$ has had a great impact on public health promotion actions. Based on the recommendation that every healthy adult should accumulate at least 30 minutes of moderate-intensity PA per day ${ }^{(1)}$, different quantification tools, such as pedometers and questionnaires, have been employed to evaluate PA patterns ${ }^{(10,11)}$. Recent studies have investigated the pedometer-measured amount of steps necessary for good health or for the "30-minute message" equivalence $^{(12-14)}$. The proposed target of 10,000 steps per day ${ }^{(15,16)}$ may represent an unattainable task for some sedentary people. Therefore, other strategies for PA improvement have been evaluated, such as the Canada on the Move campaign that suggests additional 2000 -steps/day ${ }^{(11)}$. In parallel, studies involving subjects with some chronic diseases, such as diabetes, hypertension and obesity, have focused on physiological issues associated with an enhancement of the physical activity level ${ }^{(6,16-18)}$. Despite some recent advances ${ }^{(12-15)}$, the accumulated daily steps strategy still deserves better characterization regarding the amount of steps, duration, intensity and associated physiological effects.

Considering some physiological responses to regular PA practice, the determination of the ventilatory anaerobic threshold (AT) by the respiratory gas exchange protocol ${ }^{(19)}$ may be employed as a marker of metabolic efficiency at a sub-maximal level of physical exercise. Commonly employed in sports field, the evaluation of the AT can contribute in the evaluation of physiological modifications induced by low-to-moderate physical activity. Moreover, AT could represent a reference of safety during exercise training in a reduced myocardial oxygen demand, as is usual on walking programs.

Therefore, we aimed to investigate the effects of a short-term pedometer-quantified 3500 steps per day increment on exercise tolerance at the AT in healthy insufficiently active men.

\section{METHODS}

\section{Subjects}

A sample of 19 men, aged 19 to 46 years (mean \pm sd: $31.1 \pm 9.5 \mathrm{yrs}$ ), with homogeneous clinical and cardiovascular conditions, included participants of a health promotion program sponsored by the Supreme Labour Court of 
Brazil, named "TST on the Move" (26\%), and university students (74\%). The subjects were clinically healthy, non-smokers, with a body mass index (BMI) between 18.5 and $29.9 \mathrm{~kg} / \mathrm{m}^{2}$ (mean $\pm \mathrm{sd}: 24.6 \pm 2.7 \mathrm{~kg} / \mathrm{m}^{2}$ ) and normal systolic / diastolic blood pressure (mean \pm sd: $110 \pm 9$ / $76 \pm 6 \mathrm{mmHg}$ ). All subjects were insufficiently active at baseline, as characterized by the International Physical Activity Questionnaire (IPAQ) - Portuguese version. Considering the relatively small sample size, a question was added to the questionnaire inquiring if the responses to IPAQ represented the pattern of volunteers' PA in the last two months. Volunteers should have been out of any regular exercise for the same period of time. The experimental protocol was approved by the Ethics Committee on Human Beings Research of the University of Brasília Faculty of Medicine (CEP-FM-049/2005). All subjects gave their written informed consent to participate in the study.

\section{Experimental protocol}

Volunteers were asked to refrain from caffeine and exercise for 12 hours prior to the laboratory evaluation. To characterize volunteers's clinical conditions, a complete clinical inquiry followed by an extensive physical examination and a 12-lead electrocardiogram registration was proceeded by one of the authors (LFJJ) at the beginning of the experimental session. Subsequently, each subject executed a 20 steps test to find their optimal pedometer attachment site $^{(10)}$, avoiding possible differences associated with pedometer placement in the body ${ }^{(20)}$. In all cases the pedometer was used in the midline of the right thigh, as recommended by the manufacturers.

All volunteers were instructed to use the pedometer (Yamax DigiWalker SW 700, Yamax Corp., Tokyo, Japan) during approximately 2 weeks without any habit or PA change, in order to quantify their usual daily steps pattern. The numbers of steps in both weeks, including the weekends, were registered by the volunteers during wakefulness periods on a specific paper form, and the pedometer was reset to zero every day. After this baseline period, the subjects returned to the laboratory with their daily steps records in order to start the intervention. The new daily steps target was then calculated by adding 3500 steps to the mean steps performed on weekdays at baseline. Thereafter, functional and anthropometric data were recorded and the first cardiopulmonary exercise stress test (CPX) was performed, at the Exercise Physiology Laboratory of the Faculty of Physical Education. Following this first CPX, where the anaerobic threshold (AT) was determined, the volunteers were oriented to achieve their new daily step target during 3 weeks (intervention). At the end of this period, functional and anthropometric data were evaluated again and a second CPX was performed to evaluate the intervention.

Daily steps counts and exercise tolerance before and after the intervention were pair-wised compared, each subject being his own control. Daily steps counts were analyzed separately in weekends/holidays and in weekdays. In case of missing records, data were interpolated by the number of steps reported by the same subject on a correspondent weekday. There were only 25 out of 706 monitored days (3.5\%) with missing records for all subjects.

As an inclusion criterion, volunteers had to achieve at least $75 \%$ of the calculated steps target during the intervention. A full adherence (100\%) was attainted when the volunteers were able to accumulate 3500 steps per day, 
every day during the intervention, above their own mean steps accumulated on week days at baseline. Two volunteers were not included due to cardiovascular abnormalities at the baseline evaluation and only one volunteer failed to achieve at least $75 \%$ of the established steps target and was excluded. The experimental protocol design is depicted in the Figure 1.

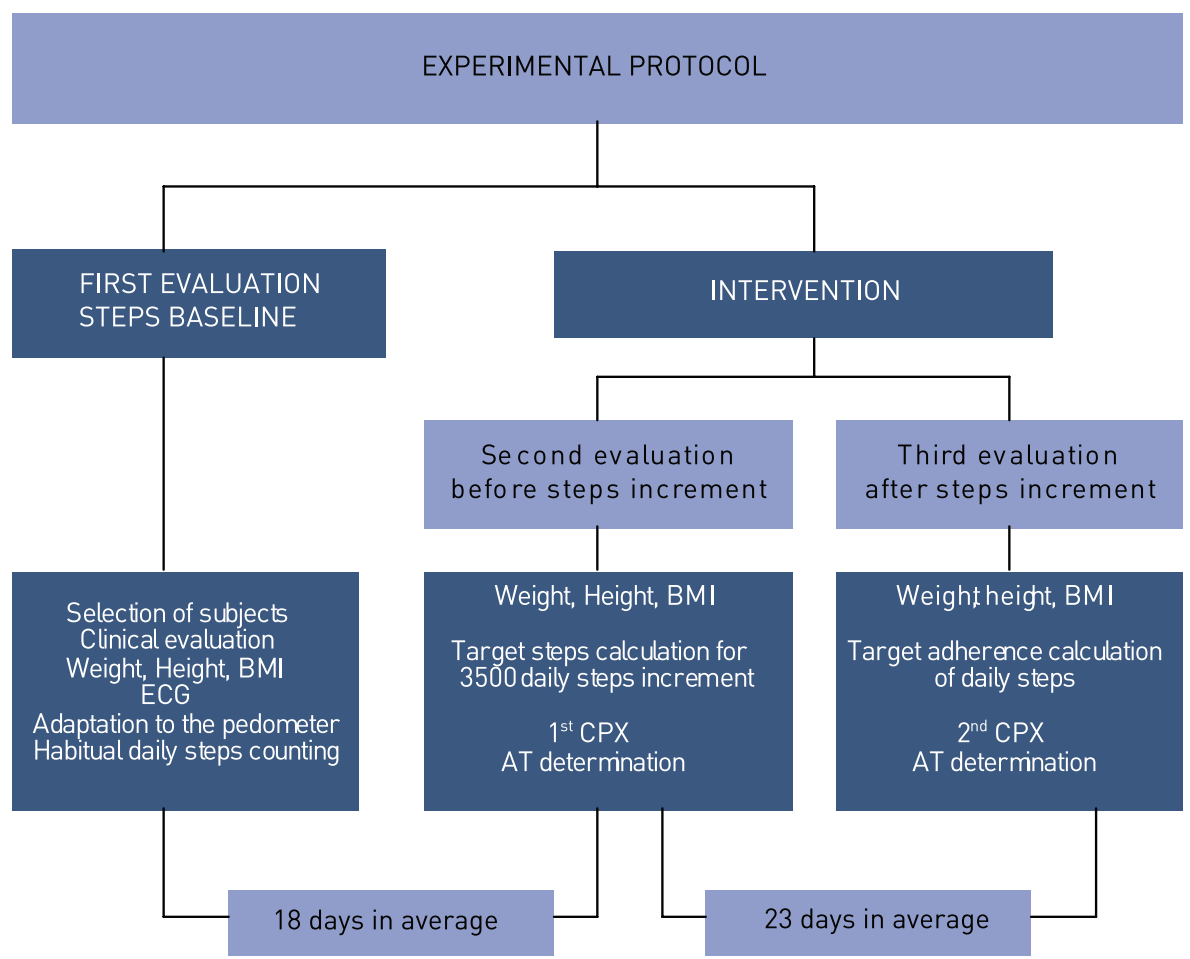

FIGURE 1 - Experimental protocol design. CPX: cardiopulmonary exercise stress test; AT: anaerobic threshold, BMI: body mass index, ECG: 12-lead electrocardiogram.

The CPX consisted of a graded submaximal treadmill exercise test, following a protocol specifically designed for this study, with the use of an Imbrasport-ATL ergometer (Imbrasport, Brazil). After a 3-minute adaptation period to the treadmill and the gases analyzer equipment, the test started at a treadmill speed of $3 \mathrm{~km} / \mathrm{h}$ and at a fixed $3 \%$ inclination. The treadmill speed was increased by $1 \mathrm{~km} / \mathrm{h}$ every 2 -minute stage until the end of the test. The CPX was interrupted one or two stages after the AT has been estimated in a online visual analysis during the test. Expired gases were collected and analyzed with a portable indirect calorimeter (AeroSport TEEM 100 Metabolic Analysis System, USA).

In accordance with the method proposed by Wasserman et $\mathrm{al}^{(19)}$, the AT was identified as the moment in which exercise intensity caused the first increment of the ventilatory equivalent for oxygen $\left(\mathrm{VE} / \mathrm{VO}_{2}\right)$ without a concurrent increment of the ventilatory equivalent for carbon dioxide $\left(\mathrm{VE} / \mathrm{VCO}_{2}\right)$, combined with the first observed inflection on the minute-ventilation (VE) curve. The final identification of the AT in each CPX was done by the same expert author (KEF), on a offline mode, only after all tests have been performed, blinded to the volunteer identity and to the order of the CPX (if at the beginning or at the end of the intervention).

To evaluate exercise tolerance, we analyzed the heart rate at AT (HR-AT), 
the oxygen uptake at AT $\left(\mathrm{VO}_{2}-\mathrm{AT}\right)$, the time spent on CPX until AT onset and the reached distance. That distance, covered until AT onset, was used to quantify the total physical performance of each volunteer, in the two CPX. Even all stages on CPX had the same length, the CPX performed before and after the intervention could attained different stages. For that reason we also analyzed the distance covered until AT in order to adjust for differences in the amount of time spent by each subject at different stages (intensities).

Sample data were tested for normality using the Shapiro-Wilk test. Considering that the majority of the data were non-normally distributed, we uniformly employed nonparametric statistics and tests, expressing the results as median and minimum - maximum values. Anthropometric and clinical data were compared between the three evaluations using the Friedman test with Dunn's multiple comparison. Medians of weekends/holidays and week days steps counts and those of all functional variables were pair-wised compared before and after the daily steps increment, using the Wilcoxon signed-rank test. Considering that each subject was his own control, with no changes on individual ages during the protocol, no adjustment for age was done when comparisons of data before and after intervention were performed. The differences were considered statistically significant when a two-tailed value was less than $5 \%(<0.05)$. The Prism ${ }^{\circledR} 4$ for Windows (GraphPad Software, Inc., USA, 2005) software package was used for data processing and analysis.

\section{RESULTS}

Resting functional variables did not change during the study period. Medians of the rest heart rate in the three evaluations varied between $59-64$ beats. $\min ^{-1}(\mathrm{p}=0.14)$, and the arterial pressure varied from 108 to $110 \mathrm{mmHg}$ for systolic ( $\mathrm{p}=0.76)$ and 72 to $78 \mathrm{mmHg}$ for diastolic $(\mathrm{p}=0.17)$. The BMI showed median values of $24.9 \mathrm{~kg} / \mathrm{m}^{2}$ in the three evaluations $(\mathrm{p}=0.79)$.

The daily steps data are show in Table 1 . Before the intervention, in daily steps baseline period, the median (minimum - maximum) of accumulated steps during weekdays was significantly higher (7780; $5370-15225$ steps) as compared to weekend days $(6683 ; 3073-14211$ steps) $(\mathrm{p}=0.01)$. Differently, during the intervention, the number of accumulated steps during weekdays $(11545 ; 8080$ - 18640 steps) was similar to the weekend ones $(11482 ; 8500$ 18300 steps) ( $\mathrm{p}=0.28)$. However, the median percent increment of daily steps was higher in weekend days $(80.5 \% ; 14.4-234.6)$ than in weekdays $(51 \%$; 2.9 - 87.8) $(\mathrm{p}=0.007)$.

The median adherence of the subjects to the protocol was $106.2 \%(83.4-$ $119.9 \%)$, which means that the proposed steps goal was attained and exceeded by $6.2 \%$. Only one subject showed adherence below $75 \%$ and was excluded from the analysis.

Comparison of cardio-respiratory variables at AT in the CPX test before and after the intervention did not show statistical differences. Median (minimum - maximum) of HR-AT in the second test was 120 beats $/ \mathrm{min}^{-1}(95-145)$ against 112 beats. $\mathrm{min}^{-1}(94-143)$ in the first one $(\mathrm{p}=0.12)$, and the $\mathrm{VO}_{2}$-AT was, respectively, $17.6 \mathrm{ml} / \mathrm{kg} / \mathrm{min}^{-1}(13.4-26.0)$ and $16.2 \mathrm{ml} / \mathrm{kg} / \mathrm{min}^{-1}(14.2-22.9)$ $(\mathrm{p}=0.15)$. 
TABLE 1 - Median, quartiles and extreme values of the number of daily steps before and after the increment intervention according to the period of week in 19 healthy insufficiently active men.

\begin{tabular}{llllllc}
\hline & \multicolumn{2}{c}{ Total steps } & \multicolumn{2}{c}{$\begin{array}{c}\text { Steps } \\
\text { during week }\end{array}$} & \multicolumn{2}{c}{$\begin{array}{c}\text { Steps } \\
\text { during weekend }\end{array}$} \\
\hline & $\begin{array}{l}\text { Before } \\
\text { intervention }\end{array}$ & $\begin{array}{l}\text { After } \\
\text { Intervention }\end{array}$ & $\begin{array}{l}\text { Before } \\
\text { intervention }\end{array}$ & $\begin{array}{l}\text { After } \\
\text { intervention }\end{array}$ & $\begin{array}{l}\text { Before } \\
\text { intervention }\end{array}$ & $\begin{array}{l}\text { After } \\
\text { intervention }\end{array}$ \\
\hline Minimum & 4700 & 8998 & 5360 & 8080 & 3073 & 8500 \\
\hline Lower quartile & 6195 & 10341 & 6001 & 10672 & 4940 & 10151 \\
\hline Median & 7295 & 11772 & 7780 & 11545 & 6683 & 11482 \\
\hline Upper quartile & 9402 & 13350 & 10205 & 14395 & 7555 & 12431 \\
\hline Maximum & 14752 & 18620 & 15225 & 18640 & 14211 & 18300 \\
\hline
\end{tabular}

* In each period the data before and after daily steps increment were pair-wised compared by the Wilcoxon signed-rank test.

However, exercise tolerance at AT enhanced after the period of steps increment. The time for attaining the AT onset was $340 \mathrm{~s}(208-436 \mathrm{~s})$ before and $359 \mathrm{~s}(179-521)$ after the intervention $(\mathrm{p}=0.027)$, and the distance covered until AT was $372 \mathrm{~m}(198-529 \mathrm{~m})$ before and $399 \mathrm{~m}(166-638)$ after it $(\mathrm{p}=0.014)$, as illustrated in Figure 2. Apart from that, sixty eight percent of the volunteers showed increment in the time and distance attained at AT.
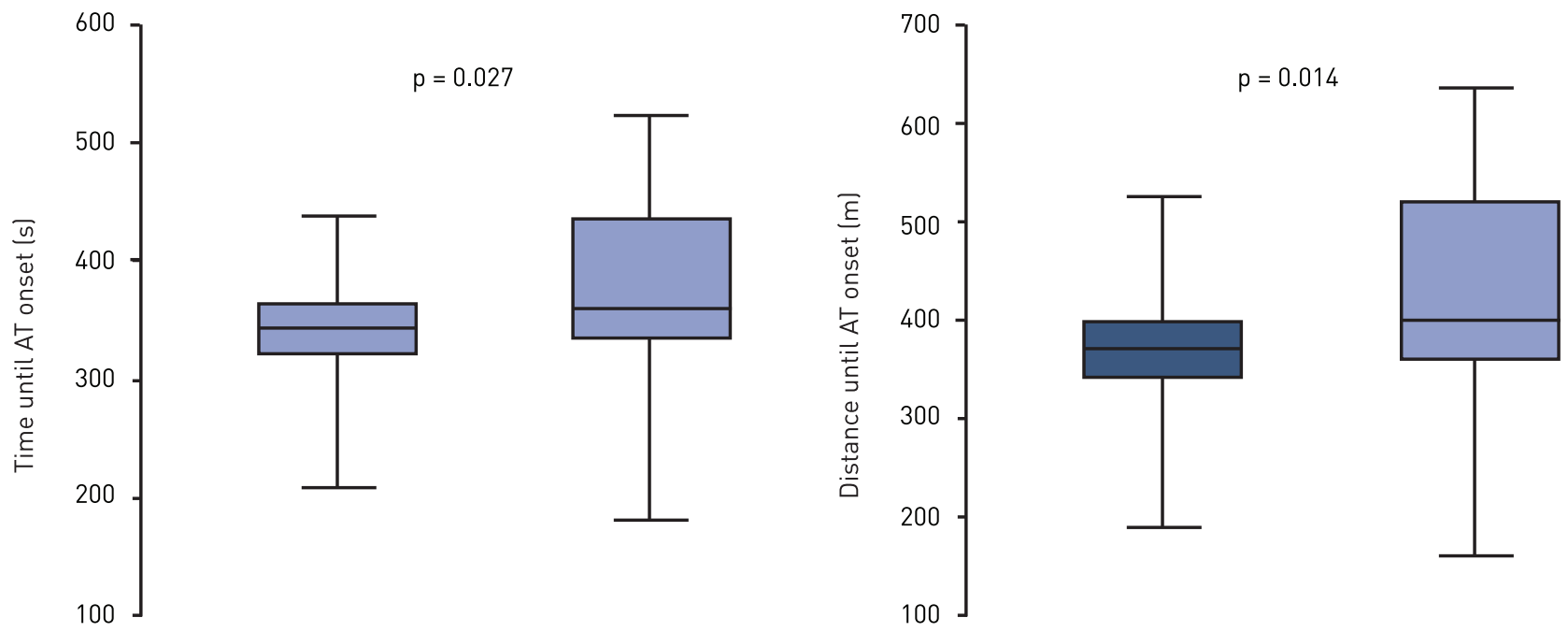

FIGURE 2 - Time (left) and distance (right) to attain the anaerobic threshold (AT) during the cardiopulmonary exercise stress testing before (CPX-1) and after (CPX-2) the 3-week intervention of increment of 3500 steps by day. For each moment are shown the median, interquartile range and extremes values for 19 subjects. The effects of the intervention were tested by the Wilcoxon test.

\section{DISCUSSION}

In this short-term analysis we found a significant improvement of exercise tolerance at the AT after a walking program that showed a high degree of adherence. The observed alterations represented a median increment of $6 \%$ in CPX time until AT onset and of $8 \%$ for the reached distance in $68 \%$ of the volunteers. Together, these findings suggest that the physiological adjustment observed had a potential impact on daily physical activities performance of the participants. The relevance of those results must be analyzed considering 
the age and the clinical status of the volunteers. The fact that healthy young and middle-aged men have showed improvement in their exercise tolerance at AT associated with a very simple and low-cost physical activity program opens good perspectives in a scenario where almost one third of worldwide adults are inactive ${ }^{(21)}$.

To explain these findings we have to consider the possibility that the subjects were in a very low fitness level at baseline. The low values of $\mathrm{VO}_{2}$-AT observed are compatible with the PA status of the volunteers and corroborate this possibility. Similarly, a recent study demonstrated that subjects improved their maximal $\mathrm{VO}_{2}$ and treadmill duration test in a 30-minute training program based on a low-intensity effort during a 12 weeks intervention period ${ }^{(22)}$. At the same time, the observed improvement of the tolerance to exercise at AT in our study was not associated with statistical changes in the $\mathrm{VO}_{2}$-AT. This was probably due to the relatively small size of the sample and/or the short time of the intervention.

Another possibility is that interventions based on daily activities, such as short and intermittent walking, are frequently dependent on both aerobic and anaerobic metabolism. In physical activities that are not continuous, an adaptation on the lactic acid buffering mechanism could have an important role on improvement of exercise tolerance at AT. In fact, accumulative data concerning the physical activity and health association shows that it is possible to attain health benefits of exercise without reaching high levels of aerobic fitness. In this idea, the amount of activity seems to prevail about the intensity and the effectiveness of the intermittent exercise is reinforced ${ }^{(23)}$. However, it should be observed that on younger the influence of PA intensity on health outcomes might prevail about the quantity of $\mathrm{PA}^{(24)}$. Apart from that, the apparent discrepancy between better exercise tolerance with similar oxygen consumption at AT could mean that we were probably facing an intermediary physiological adjustment. Because of the short intervention period, we probably saw an adjustment that was sufficient to improve the exercise tolerance based on local energy production mechanism, but insufficient to increase the central oxygen uptake.

An additional important observation was the fact that the type of intervention proposed was absolutely effective to abolish the significantly small number of daily steps usually performed on holidays/weekend days. This "weekend effect" has been already observed ${ }^{(25)}$, but in the present research it was noted only in the baseline phase. This lack of weekend effect during the intervention period may be due to the characteristics of the proposed PA intervention and confirms its efficiency. Those data reinforce the utility of a moderate daily steps increment plan as a health promoting action ${ }^{(8)}$. The pattern of daily steps observed during the baseline phase was similar to others studies $^{(8,10,15,18)}$. In this context, our observations reinforce the finding that the pattern of usual daily steps in previously healthy inactive men is far below the 10000 steps widely proposed as convenient.

Some previous studies that aimed to find equivalences between the " 30 minutes" and the "10000 steps" messages have found increment estimations around 3100 and 4000 steps $^{(13,14)}$. In the present study, the definition of the target increment in the number of steps was based on a classification suggested by Tudor-Locke and colleagues for a moderate intensity activity ${ }^{(13)}$. According to this study, the exact value obtained in the intermediate steps/ 
minute cut-off value would be 3300 steps per day to be taken above the usual. To facilitate some operational aspects with the volunteers, we chose to round it to 3500 daily-steps. This target almost completely met the public health recommendations ${ }^{(1)}$, including a minimum of physical activity (that could be the number of steps equivalent to 30 minutes) on a specific frequency (daily or at least 5 days/week), above the sedentary pattern. The only difference, purposefully included, was the fact that we did not determinate any intensity to perform the new goal of daily steps. The reason for that methodological option was to evaluate a most feasible way to accumulate daily steps. On a similar approach, Iwane and colleagues have observed that walking at least 10000 steps/days was effective in reducing blood pressure and increasing exercise capacity in hypertensive men, irrespective of exercise intensity or duration ${ }^{16}$.

Moreover, we observed a very high level of adherence to the protocol. This was probably due to the fact that the protocol was established on a walking activity, with low-to-moderate increment of the total amount of PA, done during a short intervention period. It is clear that our short-term period of analysis could represent a study limitation. However, our focus was exactly on the shift from a sedentary or an insufficiently active condition to a more active functional stage. In that sense, evaluations of short-term functional modifications may be helpful to better understand some physiological effects associated with such physical activity interventions and might be useful for long-term physical activity program planning.

It should be also outstanding that simple and low physical activity interventions, such as walking 3500 steps/day more than usual, which approximately correspond to the "30-minute" message ${ }^{(26)}$, could be an efficient strategy for modifying life habits of inactive subjects.

One limitation of our study is that it was restricted to young and middle-aged insufficiently active healthy men. Only an expectative may be sought that the observations can extend to women and subjects with older ages and to those with some clinical conditions. Other restrictions could be the short period of the intervention and the sample size. Despite the inherent limitations to evaluate long-terms behavior changes, our objective was to detect the occurrence of possible physiological short-term functional changes. It means that we were interested on the shifting period from a insufficiently active behavior to a more active condition. As to the sample, its homogeneity was privileged over its size. Rigorous clinical criteria of inclusion were carried out to ensure a group of subjects really insuficiently active and clinically healthy.

Another important issue that must be considered is the possible influence of a mechanical technique improvement or a learning effect on the second CPX as compared to the first one, since their occurrence or magnitude are still open questions on the field. On the other hand, the AT reliability has been already demonstrated in apparently healthy individuals ${ }^{(27)}$. Apart from that, every volunteer did a 3-minute adaptation period to treadmill and gases analyzer equipment on both tests. In addition, we observed a high percentage of volunteers who showed improvement on their exercise performance $( \pm$ $70 \%)$ with a high statistical level of significance. In conclusion, the possible influence of a technique improvement or a learning effect is reduced considering the observed results and the exercise protocol that was employed. Concerning to the use of pedometer, one limitation is the impossibility to 
measure activities that do not involve vertical displacement of the hip, such as those carried out by the upper members, and the possibility of misreporting of steps data. As to the precision level of data recording, the pedometer used in this study is considered as a tool with adequate accuracy in evaluating accumulated daily steps ${ }^{(14)}$. Furthermore, none of the volunteers practiced any other previous PA on a systematic fashion.

Although these relative limitations, the proposed intervention was shown to be very efficient, since the "weekend effect" had been abolished and a high level of adherence had been reached. By following the 'one-step-ahead model' ${ }^{\prime(28)}$, the intervention attended the minimal recommendations for PA pattern change in a feasible way, with potentiality for practical and easy application. It is hopeful to consider the impact of an increase of exercise tolerance on both personal and public health perspectives. Quantification of non-structured PA has been shown to be one of the challenges in the scenario of exercise program evaluation. Our data reinforce some evidences that unstructured PA, even of low-to-moderate intensity, may have important influence on health outcomes ${ }^{(29)}$.

In conclusion, the pedometer-quantified increment of 3500 steps per day above the individual usual daily steps pattern, during a 3 -week period, was effective in improving the volunteer's PA level and was associated with a significant favorable impact on exercise tolerance at AT, in previously insufficiently active young and middle-aged healthy men.

\section{Acknowledgements}

The authors thank the contributions of Dr. Maria da Conceição Bezzera Cavalcanti, director physician of Brazil Supreme Labor Court Health Services at that time, for the clinical evaluation of the volunteers. We are also grateful to Prof. Adriana Lofrano and Prof. Maria Imaculada Muniz-Junqueira of the University of Brasilia and Hospital in reviewing the English language. The technical assistance of Ms. Maria da Graça Souza, Mr. João Ronaldo de Andrade Rocha (in memoriam), Ms. Lúcia Kobayashi and Mr. Harley Azevedo Junior, and the data processing by Mr. Satir Lara Junior as scholarship of the Brasilia University Faculty of Physical Education is also gratefully appreciated.

\section{Author's contributions}

LGGP was responsible for the protocol design, data collection, statistical analysis, data interpretation and writing of the final version of the manuscript. KEF and GEM contributed for the definition of the protocol design, the definition of the exercise test protocol, the anaerobic threshold measurement, data collection and revision of the manuscript. GR, as a master degree student, helped on data collection and the definition of the exercise test protocol. LFJJ was the research project advisor, responsible for the protocol design, the statistical analysis, data interpretation and revision of the final version of the manuscript.

\section{REFERENCES}

1. Haskell WL, Lee IM, Pate RR, Powell KE, Blair SN, Franklin BA, et al. Physical activity and public health: updated recommendation for adults from the American College of Sports Medicine and the American Heart Association. Medicine and science in sports and exercise. 2007;39(8):1423-34. 
2. Morris JN, Heady JA, Raffle PA, Roberts CG, Parks JW. Coronary heart-disease and physical activity of work. Lancet. 1953;265(6795):1053-7; contd.

3. Lee IM, Shiroma EJ, Lobelo F, Puska P, Blair SN, Katzmarzyk PT, et al. Effect of physical inactivity on major non-communicable diseases worldwide: an analysis of burden of disease and life expectancy. Lancet. 2012;380(9838):219-29.

4. Bauman AE. Updating the evidence that physical activity is good for health: an epidemiological review 2000-2003. Journal of science and medicine in sport / Sports Medicine Australia. 2004;7(1 Suppl):6-19.

5. Kohl HW, 3rd, Craig CL, Lambert EV, Inoue S, Alkandari JR, Leetongin G, et al. The pandemic of physical inactivity: global action for public health. Lancet. 2012;380(9838):294-305.

6. Franklin BA. Walking: the undervalued prescription. Preventive cardiology. 2006;9(1):56-9.

7. Lee IM, Buchner DM. The importance of walking to public health. Medicine and science in sports and exercise. 2008;40(7 Suppl):S512-8.

8. Tudor-Locke C. Walk more (frequently, farther, faster): the perfect preventive medicine. Preventive medicine. 2012;55(6):540-1.

9. Shaw R, Fenwick E, Baker G, McAdam C, Fitzsimons C, Mutrie N. 'Pedometers cost buttons': the feasibility of implementing a pedometer based walking programme within the community. BMC public health. 2011;11:200.

10. Tudor-Locke CE, Myers AM. Methodological considerations for researchers and practitioners using pedometers to measure physical (ambulatory) activity. Research quarterly for exercise and sport. 2001;72(1):1-12.

11. Craig CL, Tudor-Locke C, Bauman A. Twelve-month effects of Canada on the Move: a population-wide campaign to promote pedometer use and walking. Health education research. 2007;22(3):406-13.

12. Hultquist CN, Albright C, Thompson DL. Comparison of walking recommendations in previously inactive women. Medicine and science in sports and exercise. 2005;37(4):676-83.

13. Tudor-Locke C, Sisson SB, Collova T, Lee SM, Swan PD. Pedometer-determined step count guidelines for classifying walking intensity in a young ostensibly healthy population. Canadian journal of applied physiology = Revue canadienne de physiologie appliquee. 2005;30(6):666-76.

14. Welk GJ, Differding JA, Thompson RW, Blair SN, Dziura J, Hart P. The utility of the Digi-walker step counter to assess daily physical activity patterns. Medicine and science in sports and exercise. 2000;32(9 Suppl):S481-8.

15. McCormack G, Giles-Corti B, Milligan R. Demographic and individual correlates of achieving 10,000 steps/day: use of pedometers in a population-based study. Health promotion journal of Australia : official journal of Australian Association of Health Promotion Professionals. 2006;17(1):43-7.

16. Iwane M, Arita M, Tomimoto S, Satani O, Matsumoto M, Miyashita K, et al. Walking 10,000 steps/day or more reduces blood pressure and sympathetic nerve activity in mild essential hypertension. Hypertension research : official journal of the Japanese Society of Hypertension. 2000;23(6):573-80.

17. Araiza P, Hewes H, Gashetewa C, Vella CA, Burge MR. Efficacy of a pedometer-based physical activity program on parameters of diabetes control in type 2 diabetes mellitus. Metabolism. 2006;55(10):1382-7.

18. Tudor-Locke C, Bassett DR, Jr. How many steps/day are enough? Preliminary pedometer indices for public health. Sports Med. 2004;34(1):1-8.

19. Wasserman K, Hansen JE, Sue DY, Whipp BJ. Principles of Exercise Testing and Interpretation. Philadelphia: Lea \& Febiger; 1987. 274 p.

20. Horvath S, Taylor DG, Marsh JP, Kriellaars DJ. The effect of pedometer position and normal gait asymmetry on step count accuracy. Applied physiology, nutrition, and metabolism = Physiologie appliquee, nutrition et metabolisme. 2007;32(3):409-15.

21. Hallal PC, Andersen LB, Bull FC, Guthold R, Haskell W, Ekelund U, et al. Global physical activity levels: surveillance progress, pitfalls, and prospects. Lancet. 2012;380(9838):247-57. 
22. Meyer T, Auracher M, Heeg K, Urhausen A, Kindermann W. Effectiveness of lowintensity endurance training. International journal of sports medicine. 2007;28(1):33-9.

23. Publications HMSHH. Moderate exercise: no pain, big gains. Harv Mens Health Watch. 2007;11(10):5.

24. Reichert FF, Hallal PC, Wells JC, Horta BL, Ekelund U, Menezes AM. Objectively Measured Physical Activity in the 1993 Pelotas (Brazil) Birth Cohort. Medicine and science in sports and exercise. 2012.

25. Chan CB, Ryan DA, Tudor-Locke C. Relationship between objective measures of physical activity and weather: a longitudinal study. Int J Behav Nutr Phys Act. 2006;3:21.

26. Le Masurier GC, Sidman CL, Corbin CB. Accumulating 10,000 steps: does this meet current physical activity guidelines? Research quarterly for exercise and sport. 2003;74(4):389-94.

27. Amann M, Subudhi AW, Walker J, Eisenman P, Shultz B, Foster C. An evaluation of the predictive validity and reliability of ventilatory threshold. Medicine and science in sports and exercise. 2004;36(10):1716-22.

28. Matsudo V, Matsudo S, Andrade D, Araujo T, Andrade E, de Oliveira LC, et al. Promotion of physical activity in a developing country: the Agita Sao Paulo experience. Public health nutrition. 2002;5(1A):253-61.

29. Matthews CE, Jurj AL, Shu XO, Li HL, Yang G, Li Q, et al. Influence of exercise, walking, cycling, and overall nonexercise physical activity on mortality in Chinese women. American journal of epidemiology. 2007;165(12):1343-50.

CORRESPONDING AUTHOR

LUIZ GUILHERME G PORTO

University of Brasilia Faculty of

Physical Education, Brasilia, DF.

Brazil 70910-900

Tel: $55-61-3107-2500$

55-61-9973-7141

E-mail: luizporto@unb.br 